\title{
ANÁLISE DA CLASSIFICAÇÃO APLICADA A DOCUMENTOS FOTOGRÁFICOS EM INSTITUIÇÕES DO PARANÁ
}

\author{
ANALYSIS OF CLASSIFICATION APPLIED TO DOCUMENTS IN \\ PHOTOGRAPHIC PARANÁ INSTITUTIONS
}

Aretusa Marques Barbosa

Ana Cristina de Albuquerque

\section{RESUMO}

A fotografia é uma representação que incide na credibilidade quanto aos fatos mostrados e, graças aos registros constantes e experiências fotográficas, grande parte do que conhecemos hoje de pequenos e breves momentos passados são, além de recordações, documentos históricos que nos mostram, importantes momentos que devem ser conhecidos para a construção de uma determinada memória. A presente pesquisa propõe analisar como é feita a classificação de documentos fotográficos em instituições informacionais como arquivos, bibliotecas, museus e centros de documentação visando averiguar a adequação desta atividade a documentos com particularidades próprias e que, na maioria dos casos, não têm definições específicas para seu tratamento. Sendo assim, a pesquisa se pautou no objetivo geral de analisar a atividade de classificação de documentos fotográficos em unidades informacionais e teve como objetivos específicos identificar na literatura as definições para classificação de documentos fotográficos e sistematizar os procedimentos metodológicos adotados para a classificação de documentos fotográficos.

Palavras-chave: Documento fotográfico. Classificação. Representação temática.

\begin{abstract}
The photography is a representation that focuses on credibility as those shown facts and, thanks to constant records and photographic experiments, much of what we know of small and brief moments spent are in addition to memories, historical documents show the important moments They must be known for the construction of a particular memory. This research aims to analyze how is the classification of photographic documents in information institutions such as archives, libraries, museums and documentation centers to ascertain the appropriateness of this activity the documents with its own peculiarities and that, in most cases, have no specific settings for treatment. Thus, the research was based on the general purpose of analyzing the photographic document classification activity in information units and had specific objectives identified in the literature definitions for photographic document classification and systematize the methodological procedures adopted for the photographic document classification.
\end{abstract}

Keywords: Photo Paper. Classification. Thematic representation. 


\section{SEMINÁRIO DE PESQUISA EM CIÊNCIAS HUMANAS - SEPECH \\ Humanidades, Estado e desafios didático-científicos \\ Londrina, 27 a 29 de julho de 2016}

\section{INTRODUÇÃO}

Organizar o volume de informações que estão disponíveis é um desafio. A organização da informação não pode ser ao acaso: é o resultado de todas as transformações e influências sociais, econômicas e culturais que se dão no ambiente em que circula.

A ordem, dada por seus produtores ou detentores, enquanto objetos de uso fora de uma instituição informacional reflete o sentido de uma época, de uma cultura.

O documento fotográfico está presente em diversas áreas do conhecimento e em algumas se torna um elemento quase que indispensável para pesquisas, sendo usado para observações de culturas e povos juntamente a diários de campo pela antropologia; para diagnosticar doenças com fotografias cientificas no caso da medicina; verificar as mudanças numa cidade, suas construções e urbanização na arquitetura; como objetos de valor histórico pela sociologia e historiologia. Estes são apenas alguns exemplos da importância do documento fotográfico para, junto a textos escritos, demonstrar fatos do presente ou do passado.

Trata-se de uma representação que adquiriu verdadeira credibilidade quanto a suas imagens e, graças aos registros constantes e experiências fotográficas, grande parte do que conhecemos hoje de pequenos e breves momentos passados - cidades, povos, ou seja, tudo o que foi registrado a partir do aparecimento da fotografia - são, além de recordações, documentos históricos que nos mostram, aliados a outras formas de expressão, importantes momentos que devem ser conhecidos para a construção de uma determinada memória.

A organização e classificação dadas às coleções de fotografias que vão se formando, sejam estas coleções de natureza institucional ou pessoal, refletem o pensamento de uma época. De acordo com Pavão apud Gonçalves e Marcondes (2005, p. 263):

[...] não é qualquer agrupamento ou conjunto de fotografias que se pode considerar uma coleção de fotografias. À noção de coleção preside um intuito, que lhe confere uma unidade, um significado próprio, difícil de encontrar um aglomerado de fotografias. Cada elemento que integra uma coleção faz parte de um todo, ganha sentido individual e coletivo precisamente através do conjunto. É a esta noção de um todo orgânico que podemos chamar de coleção.

A questão que se refere o autor nos remete à teoria arquivística do respeito aos fundos, ou seja, as formas de organizar e classificar documentos particulares deverem ser mantidos e respeitados pelas instituições que a recolhem, a fim de "não apagar os traços da sua organicidade, traduzida no modo como ela foi acumulada, reunida e, ainda, naquilo que foi intercambiável nessa reunião" (GONÇALVES; MARCONDES, 2005, P. 263). Tarefa difícil e que exige um trabalho de pesquisa dos profissionais envolvidos no processo de tratamento não só de arquivos como de todas as instituições que possuem acervos fotográficos.

Nesse contexto, esta pesquisa propõe um estudo sobre como a classificação é aplicada a documentos fotográficos em diferentes ambientes informacionais e espera 


\section{SEMINÁRIO DE PESQUISA EM CIÊNCIAS HUMANAS - SEPECH \\ Humanidades, Estado e desafios didático-científicos \\ Londrina, 27 a 29 de julho de 2016}

responder à seguinte questão: os procedimentos metodológicos que as classificações bibliográficas mantem em relação a documentos escritos são aplicados de forma a caracterizar a informação fotográfica adequadamente?

Sendo assim, a pesquisa se pauta no seguinte objetivo geral: estudar a atividade de classificação de documentos fotográficos em unidades informacionais. Tem como objetivos específicos: identificar na literatura as definições para classificação de documentos fotográficos; sistematizar as definições encontradas; averiguar como é feita a classificação de documentos fotográficos nas instituições propostas; comparar os resultados obtidos com manuais clássicos brasileiros que contemplam o tratamento de documentos fotográficos;

Em qualquer aspecto que se encontrem, a partir do momento em que estão em uma instituição, os documentos fotográficos necessitam de métodos e tratamentos que façam refletir, da forma mais objetiva possível, as informações que estão contidas, por vezes claras e facilmente perceptíveis, por vezes, devido a sua contextualização e produção, de difícil acesso aos profissionais envolvidos em seu tratamento.

\section{METODOLOGIA}

Esse estudo pode ser caracterizado como pesquisa bibliográfica exploratória e descritiva, uma vez que consistirá na identificação de conceitos e definições sobre o assunto proposto, coleta de dados junto às instituições e comparação dos resultados com manuais que relatam o tratamento de documentos fotográficos.

Esta pesquisa se insere no projeto de pesquisa "Tratamento temático e descritivo de acervos fotográficos: abordagem teórica e aplicada nas instituições do Paraná" coordenado pelas professora Ana Cristina de Albuquerque.

A pesquisa encontra-se em fase de levantamento bibliográfico e contextualização e entendimento do documento fotográfico no âmbito de sua representação temática com ênfase na classificação.

A próxima fase se caracterizará pela elaboração do questionário e envio às seguintes instituições: Arquivo Público de Londrina, Museu Histórico de Londrina, Biblioteca Pública do Paraná, e Centro de Estudos do Movimento de Curitiba.

Após a coleta e recebimento dos resultados será feita a análise com base nas respostas obtidas e confrontadas com manuais para construir uma discussão com base aplicada e teórica sobre os documentos propostos.

\section{DISCUSSÃO}

Classificação na visão de Vickery (1980, p. 23) "Classificar, na acepção mais simples do termo, é reunir coisas ou idéias que sejam semelhantes entre si, e separar as que apresentam diferenças". Ou seja, é a união de documentos de um determinado acervo onde se trata da informação que os documentos contêm e classifica com palavras-chaves para o acesso rápido e eficaz para a recuperação da informação que se procura. A principal função do acervo é coletar, organizar, identificar, catalogar e classificar qualquer tipo de suporte de norteia a construção do acervo e fazer dessas instituições lugares onde ficam depositados as coleções que fazem parte da história de várias culturas. Os documentos que são produzidos, dos diferentes tipos, tem o papel 


\section{SEMINÁRIO DE PESQUISA EM CIÊNCIAS HUMANAS - SEPECH \\ Humanidades, Estado e desafios didático-científicos \\ Londrina, 27 a 29 de julho de 2016}

não só de comprovar, lembrar, testemunhar fatos, mas também de, através de suas estruturas, refletir universos específicos, condensados em características e contradições que irão apresentar uma identidade própria, escrita por detentores que, ao conferir os documentos, apresentará os modos e relações com o mundo e com as pessoas da época.

A organização das informações não pode ser organizada de qualquer maneira: essa organização é resultado de influencias e transformações sociais, econômicas e culturais que circula no ambiente do acervo.

A classificação é considerada uma ponte entre o produtor e o usuário, a atividade que preservará a ligação entre a cadeia hierárquica da instituição para a facilidade da recuperação da informação e demostrará a constituição de documentos dentro dos órgãos produtores.

As pinturas nas cavernas e posteriormente a evolução das pinturas em diversos suportes são considerados os primeiros documentos fotográficos criados pelo homem. Mas foi somente no Renascimento que a pintura foi considerada oficialmente um documento. Nesse período da História, houve o aperfeiçoamento das técnicas de pintura que influenciou inventores para a criação de maquinas que registravam imagens de forma real e autentica a natureza que os cercava.

A criação da maquina fotográfica rompeu o mundo medieval e "decretou" o começo a idade moderna. Para Rouillé $(2009$, p. 38) "O dispositivo fotográfico é uma extraordinária máquina de produzir imagens-objetos mais próximos dos produtos industriais do que das realizações artesanais ou das obras artísticas".

O surgimento da fotografia causou correria entre os burgueses do século XIX, pois todos queriam ter a nova tecnologia para poder aperfeiçoa-las e garantir status perante as pessoas.

Inicialmente, as fotografias eram feitas em placas de metal e usadas para "eternizar" pessoas ou fatos importantes que ocorria na época, apenas pessoas da alta sociedade tinha acesso a essa tecnologia. Mas a fotografia se torna popular quando um comerciante - Disderi - comprou uma maquina fotográfica e, no seu estúdio fotográfico, reduziu o formato das cópias das fotografias criando os carte de visite. Ele substituiu a placa de metal por uma de vidro, fazendo assim mais cópias e diminuindo o preço das mesmas, dando a oportunidade de pessoas menos abastadas terem uma fotografia e poderem se sentir mais importantes na sociedade. Disderi deu à fotografia um caráter comercial e popular, pois antes era considerada particular da alta sociedade.

Com o passar dos séculos, a fotografia foi popularizando, evoluindo e modernizando no mundo todo. O que antes era considerado propriedade de alguns, atualmente se tornou propriedade de todos, desde os mais jovens ate os mais idosos, todos tem acesso à essa tecnologia. A fotografia, antigamente era usada somente para registrar pessoas importantes ou fatos que eram considerados relevantes para uma determinada sociedade, mas atualmente, ela é usada para tudo, se o usuário quer registrar um momento alegre, ele só precisa pegar uma maquina ou até mesmo um celular que contenha câmera digital, apertar um botão e pronto, registou o momento. Outro exemplo comum é o "selfie", uma onda jovem que dominou o mundo inteiro, a pessoa usa a câmera do celular e tira fotos de si mesmo, sem precisar da ajuda de outro para poder tirar a foto.

Assim, o documento fotográfico torna-se visível de forma verbal, além de sua forma original, pois é com essa troca de linguagem que tentamos entender no âmbito da classificação. 


\section{SEMINÁRIO DE PESQUISA EM CIÊNCIAS HUMANAS - SEPECH \\ Humanidades, Estado e desafios didático-científicos \\ Londrina, 27 a 29 de julho de 2016}

\section{RESULTADOS PARCIAIS}

Como dito acima, o trabalho se encontra na fase de levantamento e revisão de literatura. Como resultados parciais, foi elaborado um quadro com as principais definições de classificação e fotografia estudadas até o momento:

\begin{tabular}{|c|c|}
\hline AUTOR & DEFINIÇÃO \\
\hline Vickery (1980, p. 23) & $\begin{array}{l}\text { "Classificar, na acepção mais simples do } \\
\text { termo, é reunir coisas ou idéias que sejam } \\
\text { semelhantes entre si, e separar as que } \\
\text { apresentam diferenças" }\end{array}$ \\
\hline PIEDADE (1983, p. 16) & $\begin{array}{l}\text { "[...]classificar é dividir em grupos ou } \\
\text { classes, segundo as diferenças e } \\
\text { semelhanças." }\end{array}$ \\
\hline Tálamo et al (1995, p.54) & $\begin{array}{l}\text { "[...] sistema de classificação geral } \\
\text { porque apresenta a ordenação de todo o } \\
\text { conhecimento humano. Qualifica-se } \\
\text { como bibliográfica porque, ao contrário } \\
\text { dos sistemas de classificação filosóficos } \\
\text { que se preocupam com a hierarquização } \\
\text { do conhecimento e com a ordem da } \\
\text { ciência e das coisas, serve de base para a } \\
\text { organização de documentos } \\
\text { estabelecendo relações entre eles, para } \\
\text { facilitar sua localização." }\end{array}$ \\
\hline $\begin{array}{llll}\text { (SAN } & \text { SEGUNDO MANUEL, 1996, } \\
\text { p.69). } & & \end{array}$ & $\begin{array}{l}\text { "[...] la agrupación u orden de libros y } \\
\text { outro tipo de documentos según su } \\
\text { contenido, formando grupos dentro de los } \\
\text { campos de conocimiento humanos en que } \\
\text { estos campos resultan ser } \\
\text { compartimentos conceptuales." }\end{array}$ \\
\hline $\begin{array}{l}\text { Gomes et al (2006, p.19), baseado em } \\
\text { Ranganathan }\end{array}$ & $\begin{array}{l}\text { "Classificar é mapear, organizar. } \\
\text { Ranganathan alerta para a dificuldade de } \\
\text { colocar numa linha milhões e milhões de } \\
\text { idéias, com "miríades de possíveis } \\
\text { relações-imediatas-de vizinhança entre } \\
\text { elas". }\end{array}$ \\
\hline
\end{tabular}

Quadro 1 - Definições de classificação

Fonte: Elaborado pelas autoras.

Através das citações acima é possível perceber como alguns autores tratam de definir a classificação, no aqui bibliográfica e algumas diferenças nestas definições, embora sejam muito parecidas em seu objetivo geral. As definições de Vickery (1980) e Piedade (1983) são muito parecidas no sentido de dar uma noção geral do que é 


\section{SEMINÁRIO DE PESQUISA EM CIÊNCIAS HUMANAS - SEPECH \\ Humanidades, Estado e desafios didático-científicos \\ Londrina, 27 a 29 de julho de 2016}

classificação e a partir daí sugerir a percepção em relação a classificação bibliográfica quando agrupamos assuntos semelhantes. Tálamo et al (1995), refere-se ao sistema de classificação, mais especificamente neste caso a Classificação Decimal de Dewey (CDD) onde explica que é um sistema de classificação geral pois trata de todo conhecimento dividido em classes e é diferente do sistema de classificação filosófico, pois seu objetivo é a organização de documentos que pode se juntar à definição de San segundo Manuel que fala na ordenação de livros e outros documentos tendo como ponto principal seus assuntos. Por fim, temos a definição de Gomes (2006), baseada em Ranganathan, onde o autor apresenta a dificuldade em se classificar e definir, de forma uniforme, uma classificação.

Estas definições servem inicialmente para delimitarmos o capo da classificação para podermos definir também a classificação dos documentos fotográficos nas instituições que serão pesquisadas.

\begin{tabular}{|l|l|}
\hline Kossoy (2001, p. 01) & $\begin{array}{l}\text { "a fotografia é uma forma de expressão } \\
\text { cultural, na qual foram registrados do tempo, } \\
\text { aspectos como religião, costumes, habitação, } \\
\text { enfim acontecimentos sociais de diversas } \\
\text { naturezas, foram objetos documentados } \\
\text { através da imagem." }\end{array}$ \\
\hline "O dispositivo fotográfico é uma \\
extraordinária máquina de produzir imagens- \\
objetos mais próximos dos produtos \\
industriais do que das realizações artesanais \\
ou das obras artísticas"
\end{tabular}

Quadro 2 - Definições sobre Fotografia

Fonte: Elaborado pelas autoras.

Kossoy (2003) define fotografia como um registro da passagem do homem através do tempo na história da humanidade, a fotografia registra fatos importantes, de 


\section{SEMINÁRIO DE PESQUISA EM CIÊNCIAS HUMANAS - SEPECH \\ Humanidades, Estado e desafios didático-científicos \\ Londrina, 27 a 29 de julho de 2016}

todos os vínculos possíveis que o homem pode fazer. Rouillé (2009) expõe que os dispositivos são ótimos para registros "fiéis" de pessoas ou lugares, já as pinturas não, porque "distorcem" a visão que está sendo representada. Albuquerque e Madio (2013) discute que a fotografia é uma tecnologia que cria e reproduz imagens rapidamente e por causa disso, ela tem sua própria linguagem expressiva, sendo assim, a fotografia apresenta condições únicas que determina seu tratamento nas unidades de informação. Boccato e Fujita (2006) define que fotografia é um documento que transmite informação registrada em suporte de papel ou eletrônico, construindo assim a história, cultura e educação de determinada sociedade.

Essas definições de fotografia foram selecionadas e analisadas para serem mostradas de forma que a compreensão sobre a fotografia seja melhor apreendida, de modo que fique mais simples a sua função e significado.

\section{CONSIDERAÇÕES FINAIS}

Pode-se concluir que a fotografia está intensamente presente em nosso cotidiano, seja como uma simples selfie ou como um registro de algo ou acontecimento. Tudo o que acontece atualmente tem a fotografia como forma de registro e prova documentada de algo. Por isso a necessidade de transformar a fotografia em documento e classifica-la dentro de um acervo, porque os usuários poderão ter acesso à essas fotos futuramente.

Mas a classificação dessas fotos não é tão fácil porque com a Internet, a distribuição e compartilhamento de imagens é extremamente veloz e difícil monitoramento. Um grande exemplo dessa velocidade são as redes sociais existentes atualmente como, Facebook, Tumblr, Twitter, Instragram, Kik, Snapchat, MySpace, Telegram, WhatsApp, entre outros. Sendo o Instagram e Snapchat os mais usados para a divulgação de imagens e vídeos amadores ou profissionais. Sendo assim, o campo da classificação de documentos fotográficos terá que se expandir para poder estudar os avanços no campo da fotografia. As classificações arquivísticas ou bibliográficas começavam a prever sobre o surgimento de documentos imagéticos, mas não tem uma estrutura organizacional pronta e eficaz para a sua aplicação nestes tipos de documentos. Pesquisas realizados neste campo do conhecimento seria de grande importância, pois as classificações têm que evoluir junto com a tecnologia.

Sendo assim, a classificação tem a missão de analisar as fotografias que são produzidas todos os dias e organiza-las de forma que possam ser recuperadas posteriormente para os usuários poderem usar sem muitos transtornos ou problemas, mas uma forma de classificação seria o uso dos vários tipos de classificações mencionados no artigo, por que, com isso, ficaria mais fácil e acessível o manuseio dessas imagens.

\section{REFERÊNCIAS}

ALBUQUERQUE. Ana Cristina de; MADIO, Telma Campanha de Carvalho. Fotografia e classificação: abordagem em arquivos, bibliotecas e museus. In: IV Encontro Nacional de Estudos da Imagem. I Encontro Internacional de Estudos da Imagem. Anais... Londrina, p. 208-227. 2013. 


\section{SEMINÁRIO DE PESQUISA EM CIÊNCIAS HUMANAS - SEPECH \\ Humanidades, Estado e desafios didático-científicos \\ Londrina, 27 a 29 de julho de 2016}

BOCCATO, Vera Regina Casari; FUJITA, Mariangela Spotti Lopes. Discutindo a análise documental de fotografias: uma síntese bibliográfica. Cadernos BAD $\mathrm{Z}$ (2006), p. 85-100.

GOLÇALVES, Cássia Denise; MARCONDES, Marli. A coleção fotográfica V-8. In: Anais do Museu Paulista: História e Cultura Material, São Paulo, v.13, n.1, p.253-269. jan.jun., 2005.

GOMES, Hagar Espanha; MOTTA, Dilza Fonseca; CAMPOS, Maria Luiza de Almeida. Revisitando Ranganathan: a classificação na rede. Rio de Janeiro, 2006. Disponível em: <http://www.conexaorio.com/biti/revisitando/revisitando.htm $>$. Acesso em: 25 de jan. 2015.

KOSSOY, Boris. Fotografia e história. São Paulo: Ateliê Editorial, 2001.

PIEDADE, M. A. Requião. Introdução à teoria da classificação. 2.ed. Rio de Janeiro: Interciência, 1983. 221p.

ROUILLÉ, André. A fotografia: entre documento e arte contemporânea. São Paulo: Senac, 2009.

SAN SEGUNDO MANUEL, Rosa. Sistemas de organización del conocimiento: la organización del conocimiento en las bibliotecas españolas. Madrid: Imprenta Nacional del Boletín Oficial del Estado, 1996.

TÁLAMO, Maria de Fátima Gonçalves M. et al. Vamos perseguir a informação. Comunicação e Educação, São Paulo, v.4, p.52-57, set./dez. 1995

VICKERY, Brian C. Classificação e indexação nas ciências. Tradução de M.C.G. Pirolla. Rio de Janeiro: BNG/Brasilart, 1980. 274p. (Coleção biblioteconomia, documentação, ciência da informação). 